\title{
NOTE ON PROFESSOR J. LAIRD'S TREATMENT OF SENSE PRESENTATIONS
}

\author{
BY J. E. TURNER.
}

Professor LaIRD's article ${ }^{1}$ is concerned with the origin of the whole of knowledge, which at every stage however advanced maintains its connexion with our sense experience of the material world. His able treatment appears to furnish further evidence that any theoretical isolation of sense data (as such) from the total apprehended content is much more difficult than is generally admitted. This becomes clear, I think, if we recognise that the original mind content-the "vague voluminous sensory mass" (p. 278)-even though transformed or transcended, always persists as a constituent of experience, and further that the development from this of the higher forms of knowledge is essentially continuous. It is therefore impossible ever to demarcate absolutely, within the total apprehended content, those elements, and those alone, which are contributed by sense, for these have become so interwoven with and penetrated by the products of higher activities that their isolation could be effected only by the abolition of all conscious processes except those initiated by the sense organs alone. This again at once raises the question-What exactly is the 'sense organ'? Plainly it is one thing for physiology, and quite another for psychology; for the latter cannot disregard the connexion between its nerve structures and the cerebral centres; these for psychology all function together, so that it becomes impossible to formulate any perfectly general characters of 'sense content'; as Professor Laird expresses it, perceived content "differs for different subjects according to the character of their several minds" (p. 264); and hence arises the difficulty attending its description to which he alludes on p. 266 , and which is really due to the impossibility of expressing in general terms characteristics which are essentially individual and exclusively peculiar.

All that appears feasible therefore is the merely provisional ascription of average characters to a theoretically average experience, leaving

1 This Journal, 1919, 1x. 261.

J. of Psych. $\mathbf{x}$. 


\section{Note on Prof. Laird's Treatment of Sense Presentations}

room in the case of every individual for very wide limits of departure from this average; in the same way e.g. as the definition of a biological species aims at no more than an expression of average characters, from which subspecies, varieties and individuals themselves always differ; and any such interpretation of sense data (meaning by this term "the objects with which we are directly acquainted in sensation and perception" (p. 265)) must be governed by two main principles. In the first place, since developed knowledge always has as its direct object the real world, and since this knowledge has arisen by continuous and insensible gradations from the primal 'sensory mass,' every perceived content therefore must be no other than a portion or aspect of the real world; and secondly, its apprehension must be directly dependent in the main on the activity of sense organs.

I am not sure that Professor Laird admits this first principle to be more than either a mere possibility, or a matter of indifference to psychology,--" appearances may in all cases be part of the objective world"; they are "facts which the psychologist is bound to take at their face value" (pp. 264, 265)1. True; but then what is their "face value"? Exactly as the face value of gold currency cannot be severed by the economist from the underlying world of commerce, so the face value of sense data includes their identity with that part of the real material world which is apprehended by means of the sense organs; it is from this real world that they are always delimited by the psychologist in the first instance in order to constitute the sphere (really more or less arbitrary) of his investigations; and to exclude this fact as to their origin from their face value is to constitute them at once into a fictitious category which it then becomes impossible to describe, classify or relate, simply because all the requisite terms derive their significance from the real world which has however, been made inaccessible by its prior exclusion.

That this is true becomes obvious, I think, when we consider Professor Laird's ascription of meaning to sense data as part of their face value- "meaning belongs to the presentation in precisely the sume sense as the colour and the shape" (p. 267). The italics here are my own, and are intended to bring out the importance of the second basal principle determining our consideration of sense data. For if we admit that sense presentations as such have meaning, still this cannot be in the same sense as shape and colour; for while our consciousness of these latter depends

1 Cf. also Problems of the Self, 28, 29, 55, 
primarily and directly on the sense organs, the consciousness of meaning, even if it can truly be said to depend on sense organs at all, is always indirect and derivative. The sense organs, i.e., can never in themselves alone arouse any consciousness of meaning, which is always the result of mental processes higher than sense, even though they operate on content apprehended through sense'. The primary 'sensory mass' from which all experience originates has never, as sensory, any true meaning whatever; meaning can arise only through the free play of recollection and imagination becoming co-ordinated into systematic memory and conception. But, though meaning and the purely sensed content differ thus widely in their modes of origin, still they become so indissolubly combined that all perceived content may be said (but from this standpoint only) to have inherent meaning as part of its face value; perception indeed may be regarded as the conferring of meaning upon sensed content; for until meaning arises, nothing is perceived, though somewhat may be sensed; on the other hand if sensed content be absent, we may still retain meaning, but not in perception.

But if meaning is a legitimate element in all presentations, then its limits in any given instance are purely arbitrary; we cannot i.e. lay down in advance any general "limitation to presented meanings" which, as a distinct class or category, are never transcended. Certainly the variety and vividness of sensed content cause a natural or unconscious tendency to exclude from our analysis of presentations as much content as possible other than the vivid sense content itself; but this procedure has no foundation whatever in principle, and is but the expression of an economy of mental energy-we reduce deliberate thinking as much as possible, and thus respond to sense stimuli as automatically as we can. Such meaning as any presentation exhibits always appears therefore to be as inherent therein as its purely sensible elements; but at the same time this can attain a very wide range, and a modicum of purely sensed content may be submerged as it were in a mass of meaning to such an extent that the usual proportions are quite reversed, and it then becomes a difficult problem to determine how much of the total apprehended content may properly be called a presentation. Thus when the faintest of heart beats indicates life and hope-when a slight precipitate determines innocence or guilt-how much (if we admit meaning at all) is presentation, and how much not? Professor Laird again instances the sparks at a firework display as having an unques-

1 Cf. Problems of the Self, 58 n.: "Probably thero is no object sensed which is not also judged." 


\section{Note on Prof. Laird's Treatment of Sense Presentations}

tionable presented meaning, in so far as "relation to other parts of the presented field" is apprehended (p. 267). But let us take the case of a signaller receiving a code message by means of faint and distant flashes; how much of the total meaning is here presented? and if not the whole, what general principle governs our limitation? Such a question is obviously fundamental to the theory of the nature of knowledge, and to the rôle therein of perception, conception and thought. It is true that "cognition is the guide of all movement" (p. 275); but our problem is concerned with the analysis of cognition itself, and the determination, so far as is possible in general terms, of the elements contributed to it by the different grades of conscious activity; so that this statement leaves the origin of meaning an open question.

Again, if sense data as such include meaning, it is difficult to understand how they can be other than continuants, at least to some degree ${ }^{1}$. It is true that "whatever is perceived is felt to be fragmentary" (p. 279), but a content though fragmentary may still be continuous or enduring; but if further it contains inherent meaning, it must necessarily possess some measure of continuity. For meaning consists essentially in the transcendence of the merely given - of the merely momentary; the mind cannot grasp a meaning which has no persistence or continuance whatever. But in order to constitute a sense presentation, it is obvious that some sensed content must also exist together with the meaning, for otherwise nothing is perceived; and since every presentation (as such) is for the mind an individual whole, it must as a whole participate in the continuance possessed by its inherent meaning. And when Professor Laird comes to consider temporal meaning, he abandons his principle of absolute discontinuance (p. 268); but here, as with meaning, c'est le premier pas qui coute; and if presentations be admitted to possess any degree, however slight, of continuance, there is then no difficulty in principle in regarding them as sharing, mutatis mutandis, in the real continuity of the material world, of which they themselves are indeed parts.

Such a view appears to simplify very much the whole problem of presentations; for we may supplement the realism which Professor Laird advocates ${ }^{2}$ by regarding sense data as always fragments or (perhaps better) aspects of the physical world, determined (for psycho$\operatorname{logy}$ ) to be sense data by those conditions under which they are always

\footnotetext{
1 "Sense presentations are not continuants... our descriptions of presentations are not meant to convey the implication that these are even potentially continuants" (p. 266).

2 Mind, October, 1919.
} 
and necessarily presented to a consciousness debarred by its finitude from an immediate apprehension of the whole of reality. Nevertheless it is always reality which confronts consciousness, from the primitive undifferentiated content we call 'sensory,' to the perceived world of the developed intelligence in which perception, itself always fragmentary, is supplemented by conception and thought. Such a method of treatment plainly permits, and even anticipates, the existence of illusion, hallucination and error, for it regards knowledge as being, certainly in actuality and possibly even in principle, incomplete and defective.

(Manuscript received 4 January, 1920.) 